\title{
The centre and periphery relations in international stock markets
}

\section{Hakan Berument , Nergiz Dinçer \& Hasan Olgun}

To cite this article: Hakan Berument, Nergiz Dinçer \& Hasan Olgun (2006) The centre and periphery relations in international stock markets, Applied Financial Economics Letters, 2:6, 365-370, DOI: 10.1080/17446540500461802

To link to this article: http://dx.doi.org/10.1080/17446540500461802

曲 Published online: 19 Dec 2006.

Submit your article to this journal $₫$

Џ Article views: 22

Q View related articles ๘

Citing articles: 1 View citing articles $\square$ 


\title{
The centre and periphery relations in international stock markets
}

\author{
Hakan Berument ${ }^{\mathrm{a}, *}$, Nergiz Dinçer ${ }^{\mathrm{b}}$ and Hasan Olgun ${ }^{\mathrm{c}}$ \\ ${ }^{a}$ Department of Economics, Bilkent University, Ankara, 06800, Turkey

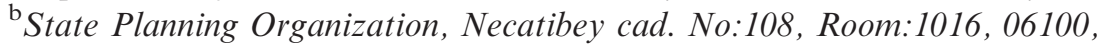 \\ Ankara, Turkey \\ ${ }^{\mathrm{c}}$ Department of Economics, Baskent University, Baglica Kampusu, Ankara, \\ 06530, Turkey
}

Encouraged by the findings of the recent studies it is argued that a kind of centre-periphery relation has been emerging between the equity markets of the developed and less developed countries. To test the argument the VAR model is employed with block exogeneity. Empirical results show that S\&P500 returns, representing the centre, affect the equity markets of the emerging markets either instantaneously or with a time lag depending on their geographical location.

\section{Introduction}

Eun and Shin (1989), and Arshanapalli and Doukas (1993) report that following the 1987 collapse, the interrelations between the USA and global stock markets have intensified. The general feeling among the researchers in this area is that the increased interconnectedness is primarily due to globalization, which is largely proceeding on two lines; trade flows and capital inflows. World Bank tables show that the volume of world trade as a share of world GDP has been increasing since the Second World War. This has largely been due to the trade liberalization efforts undertaken both by the developed and developing countries. Similarly, due to the liberalization of the capital accounts and the elimination of foreign exchange controls by the developing countries, capital inflows among countries have also been increasing. Investing in the stock market of an emerging market is a form of capital outflow, which gives rise to a kind of linkage between the capital exporting country and the capital importing developing country whose nature has not yet been clearly understood.
The existing literature on the linkages among stock markets suggest that, a kind of centre periphery relation is emerging on the global scene where the markets of the richest countries such as the USA and Japan are leading or dominating their peripheries. This study aims to show that there is indeed such a centre periphery relation between the US stock market and 15 emerging markets. It shows that there are statistically significant linkages between the S\&P500 returns and 15 emerging markets. However, the latter do not constitute a uniform block in their responses to the developments in the S\&P500. The initial response to an innovation in the S\&P500 of the Latin American countries such as Argentina, Brazil, Chile, Mexico, Peru and Venezuela is different than the initial response of the Asian countries such as Malaysia, Philippines, Singapore, Taiwan, Thailand and a Middle East country: Turkey.

This conclusion does not fully overlap with the sometimes conflicting conclusions of the past studies which can be divided into two broad categories. While some studies confirm the existence of statistically significant linkages between the global markets, there are others, which reject any linkage.

*Corresponding author. E-mail: berument@bilkent.edu.tr 
Kasa (1992) and Arshanapalli and Doukas (1993) have found bivariate cointegration of the US and European markets. Cheung and Mak (1992), Liu and Pan (1997) and Wu and Su (1998) have shown that both US and Japanese stock markets affect the stock markets of the Asian countries. Sewell et al. (1996) show that there are varying degrees of integration between the Pacific Rim equity markets and the US market. Similarly Cha and Oh (200) have shown that the US and Japanese markets affect Hong Kong, Korea, Singapore and Taiwan. Gilmore and McMannus (2002) have reported a correlation between the USA and three central European markets: the Czeck Republic, Hungary and Poland.

In sharp contrast to these findings there are some studies, which reject any international linkage among the markets. For instance, Byers and Peel (1993) and Kanas (1998) have reported that there is no linkage between the US and European markets. By the same token Ghosh et al. (1999) have also reported that they could not find any effect of the USA and Japan on the stock markets of Taiwan and Thailand. Following a different approach, Felix et al. (1998) have found no long-run comovement between the USA and a number of emerging markets.

The literature referred to above utilizes two different techniques: Cointegration tests and Vector Autoregressive (VAR) models. Cointegration tests capture the long-run relationships among the markets but do not allow for short-run interactions. On the other hand, the VAR technique enables the researcher to analyse the dynamic interactions among markets.

Since this study seeks to assess the short-run interactions and dynamic interrelations between the stock market of the centre (US) and the periphery (15 emerging markets) the VAR model will be used. This model has certain advantages over the single or multiple equations model. It may not always be possible to specify, let alone estimate, the underlying structural equation(s). Especially if one seeks to understand the linkages between two geographically separated stock markets this is an almost impossible task. In such situations the VAR model comes handy. In the absence of a well specified structural equation, it enables the researcher to understand the empirical regularities embedded in the time-series data. Another advantage of VAR is that it has higher explanatory power than a single equation model.

This study utilizes an identified VAR model with block exogeneity. It takes the USA as the centre (large country) and the emerging markets as periphery (small economies). Thus, developments in the US market are allowed to affect the emerging markets, but not vice versa. This assumption can not be introduced into the standard VAR model. Hence, we employ the VAR with block exogeneity.

The rest of the paper is organized as follows. The next section explains the methodology utilized and the data used. The third section evaluates the empirical evidence and the final section concludes.

\section{Methodology}

The basic assumption of the paper is that the US stock market affects the stock markets of the emerging countries but not vice versa. The US stock market follows its own dynamics while the emerging markets are affected by their own lags and developments in the US market. Accordingly instead of the conventional VAR we utilize the block exogeneity model proposed by Cushman and Zha (1997), which can be specified as:

$$
A(L) y(t)=\varepsilon(t)
$$

where, $A(L)$ is an $m \times \mathrm{m}$ matrix polynomial in the lag operator $L, y(t)$ is the $m \times 1$ observations vector, and $\varepsilon(t)$ is the $m \times 1$ vector of structural disturbances. The model is explicitly specified in Equation 2:

$$
\begin{aligned}
y(t) & =\left[\begin{array}{l}
y_{1}(t) \\
y_{2}(t)
\end{array}\right], \quad A(L)=\left[\begin{array}{cc}
A_{11}(L) & 0 \\
A_{21}(L) & A_{22}(L)
\end{array}\right] \\
\varepsilon_{t} & =\left[\begin{array}{l}
\varepsilon_{1}(t) \\
\varepsilon_{2}(t)
\end{array}\right]
\end{aligned}
$$

In Equation 2 it is assumed that $\varepsilon(t)$ is uncorrelated with $y_{t-j}$ for $j>0$ and $A(0)$ is non-singular. Block exogeneity is represented by $A_{12}(L)$ in the matrix, which is zero. This means that $y_{1}(t)$ is exogenous to the second block both simultaneously and also for lagged values. To calculate the standard errors of the impulse response functions, the modified error bands of Bernanke et al. (1996) are used for the maximum likelihood estimation (MLE).

The observation vector and the matrix are such that $y_{1}=(\mathrm{US}$ stock exchange $), y_{2}=($ Emerging market stock exchange). As suggested by Bayesian information criteria, the longest lag order of the identified VAR model is 5 for 15 specifications. For uniformity, lag order of 5 is taken for all countries. The error bands are generated with 5000 Monte Carlo draws for the impulse responses.

The daily US dollar value of the indexes of the emerging markets, as well as the S\&P500 index, has been collected from Datastream. However, simply because the stock exchanges of the latter group of countries have began their operations at different dates, the data start at different dates, as shown in 
Table 1. Emerging market stock exchange indices

\begin{tabular}{lll}
\hline Emerging market & Stock exchange index & Beginning of the index \\
\hline Argentina & Merval & 2 August1993 \\
Brazil & Bovespa & 8 October 1994 \\
Chile & Chile General (IGPA) & 1 December 1990 \\
China & Shanghai SE Composite & 15 September 1993 \\
Indonesia & Jakarta SE Composite & 24 January 2001 \\
Malaysia & Kuala Lumpur SE (EMAS) & 11 August 1997 \\
Mexico & IPC (BOLSA) & 11 October 1994 \\
Peru & Lima SE General (IGBL) & 3 June 1991 \\
Philippines & Philippines SE Composite & 2 January 1986 \\
Singapore & Singapore Straight Times (NEW) & 1 January 1990 \\
South Korea & Korea SE Composite (KOSPI) & 1 January 1985 \\
Taiwan & Taiwan SE Weighted & 6 January 1992 \\
Thailand & Bangkok SET & 2 July 1996 \\
Turkey & ISE National100 & 1 January 1988 \\
Venezuela & Venezuela SP General & 1 April 1993 \\
\hline
\end{tabular}

Source: Datastream.

Table 1 along with the local names of the price indices used.

\section{Empirical Results}

Impulse responses obtained for the full period of the data reported in the Figure in alphabetical order of the countries. The $90 \%$ confidence bands are calculated using the bootstrap method with 5000 draws and the middle line represents the median of the draws.

A careful examination of the impulse response functions indicate that with regard to the pattern of their responses to the developments in the US equity market the 15 countries can be divided into three groups. The Latin American countries; Argentina, Brazil, Chile, Mexico and Venezuela constitute the first group. A one standard deviation shock to the S\&P500 raises the equity markets of all these countries instantaneously. Within this group Brazil seems to be the most affected and Venezuela the least affected country. However, in all these markets the effect dies out quickly or gradually. It dies out after a day in Argentina, after two days in Brazil, Peru and Mexico, after three days in Chile and after four days in Venezuela.

Asian countries; Indonesia, Malaysia, Philippines, Singapore, South Korea, Taiwan, Thailand and Turkey constitute the second group. A one standard deviation shock to the S\&P500 index affects the stock markets of these countries not instantaneously, but with a time lag. In response to a shock the indexes of these markets initially rise and then decline.
This is due to the time lag between the USA and Asia. The stock markets in Asia open after the New York Stock Exchange closes. Hence, the effects of a development in S\&P500 can only be observed after a day in Asian markets. Partial exceptions to this rule are Singapore and Taiwan where the instantaneous adjustment seems to be stronger relative to the other Asian countries.

China by itself constitutes the third group. A one standard deviation shock to S\&P500 affect the Shanghai SE Composite after three days and dies out quickly. This may be due to the fact that China is a large county or it may be that foreign ownership in this market is not considerable.

Some researchers have noted that the interconnectedness between the equity markets of the advanced countries and the emerging markets have tended to intensify following the 11 September 2001 incident. To test for this we have repeated the above analysis for the post 1 January 2002 period. The results are mostly parallel to the full sample results. They are not reported here to save space but are available from the authors upon request.

\section{Conclusions}

This study argues that a kind of centre periphery relation has been emerging between the equity markets of the advanced countries and emerging markets. To test for this argument the VAR technique has been used with block exogeneity. Empirical results for 15 emerging markets have suggested that a development in the New York 
Stock exchange does affect the stock exchanges of the emerging markets either instantaneously or with a time lag depending on the geographical location of the latter markets.

\section{Acknowledgements}

The views presented here are those of the authors; they do not necessarily reflect the official position of the State Planning Organization or its staff.

\section{References}

Arshanapalli, B. and Doukas, J. (1993) International stock market linkages: evidence from the pre- and postOctober 1987 period, Journal of Banking \& Finance, 17, 193-208.

Bernanke, B. S., Hall, R. E., Leeper, E. M., Sims, C. and Zha, T. (1996) What does monetary policy do?, Brookings Papers on Economic Activity, 2, 1-78.

Byers, M. D. and Peel, D. A. (1993) Some evidence on the interdependence of national stock markets and the gains from international portfolio diversification, Applied Financial Economics, 3, 239-42.

Cha, B. and Oh, S. (2000) The relationship between developed equity markets and the Pacific Basin's emerging equity markets, International Review of Economics and Finance, 9, 299-322.

Cheung, Y. L. and Mak, S. C. (1992) The international transmission of stock market fluctuation between the developed markets and the Asian-Pacific markets, Applied Financial Economics, 2, 43-7.
Cushman, D. O. and Zha, T. (1997) Identifying monetary policy in a small open economy under flexible exchange rates, Journal of Monetary Economics, 39, 433-48.

Eun, C. S. and Shim, S. (1989) International transmission of stock market movements, Journal of Financial and Quantitative Analysis, 24, 241-56.

Felix, A. O., Dufresne, U. B. and Chatterjee, A. (1998) Investment implications of the Korean financial market reform, International Review of Financial Analysis, 7, 83-95.

Ghosh, A., Saidi, R. and Johnson, K. H. (1999) Who moves the Asia-Pacific stock markets - US or Japan? Empirical evidence based on the theory of co-integration, The Financial Review, 34, 159-70.

Gilmore, C. G. and McMannus, G. M. (2002) International portfolio diversification: US and Central European equity markets, Emerging Markets Review, 3, 69-83.

Kanas, A. (1998) Linkages between the US and European equity markets: further evidence from cointegration tests, Applied Financial Economics, 8, 607-14.

Kasa, K. (1992) Common stochastic trends in international stock markets, Journal of Monetary Economics, 29, 95-124.

Liu, Y. A. and Pan, M. (1997) Mean volatility spillover effects in the US and Pacific-Basin stock markets, Multinational Finance Journal, 1, 47-62.

Sewell, S. P., Stansell, S. R., Lee, I. and Below, S. D. (1996) Using chaos measures to examine international capital market integration, Applied Financial Economics, 6, 91-101.

Sims, C. A. (1992) Interpreting the macroeconomic time series facts: the effects of monetary policy, European Economic Review, 36, 975-1000.

$\mathrm{Wu}, \mathrm{C}$. and $\mathrm{Su}, \mathrm{Y}$. (1998) Dynamic relations among international stock markets, International Review of Economics and Finance, 7, 63-84.

Zha, T. (1999) Block recursion and structural vector autoregressions, Journal of Econometrics, 90, 291-316.

\section{Appendix}
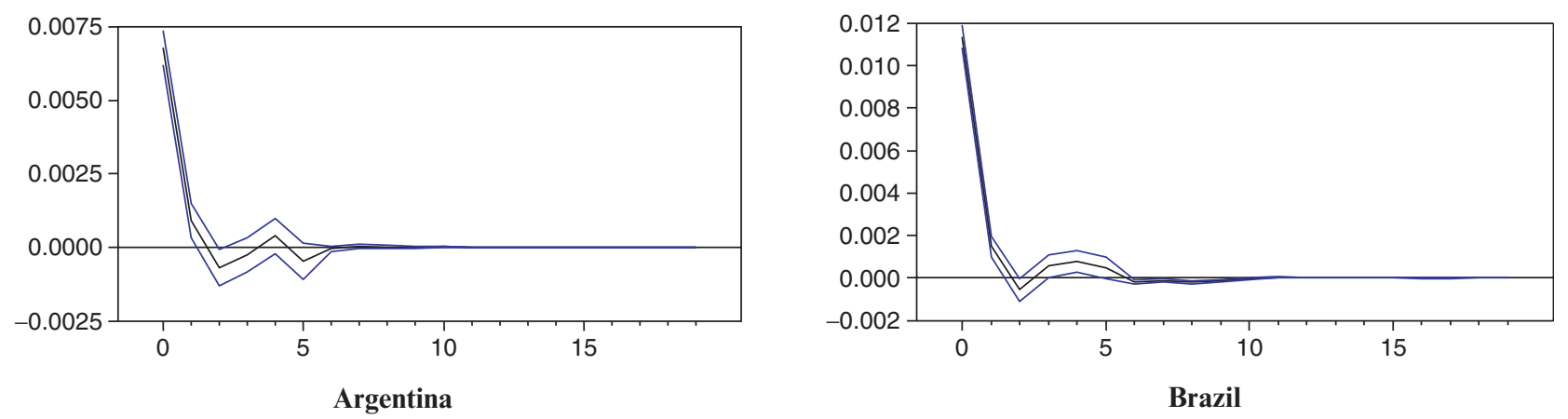

Fig. 1. Impulse responses of periphery stock markets to the US equity market. 

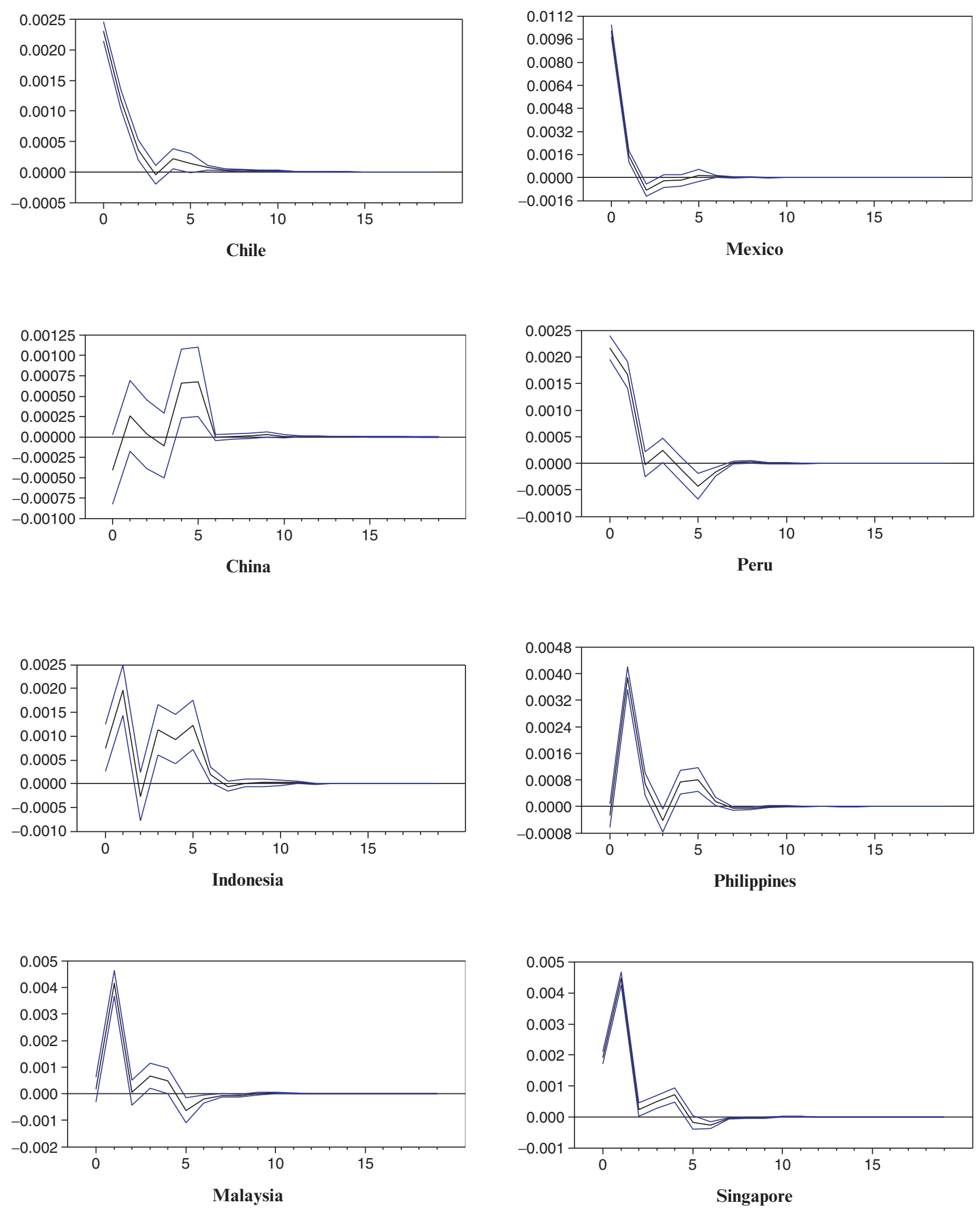

Fig. 1. Continued. 

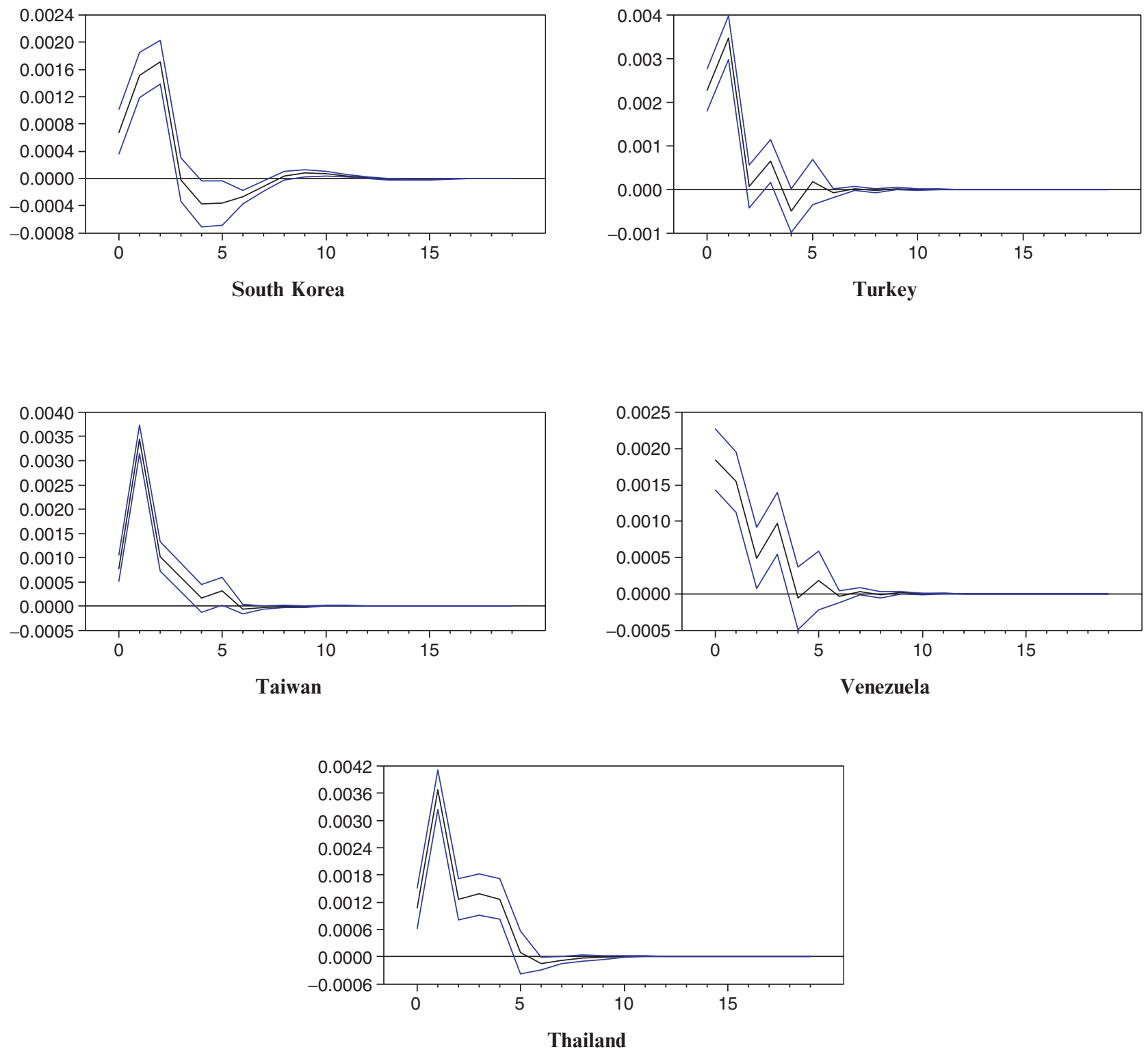

Fig. 1 continued. 